\title{
Descriptive Study
}

\section{Neuropathic Pain in Spinal Cord Injury}

\author{
Güldal F Nakipoglu-Yüzer, MD, Nermin Atçı, MD, and Nese Ozgirgin, MD
}

From: Ankara Physical Medicine
and Rehabilitation Education and Research Hospital, Ankara,

Turkey.

Dr. Nakipoglu-Yuzer and Dr. Ozgirgin are Physiatrists and Associate Professors Ankara Physical Medicine and Rehabilitation Education and Research Hospital, Ankara, Turkey. Dr. Acti is a Physiatrist with the Ankara Physical

Medicine and Rehabilitation Education and Research Hospital, Ankara, Turkey.

Address Correspondence: Güldal F Nakipoglu-Yüzer, MD Physiatrist, Associate Professor Ankara Physical Medicine and Rehabilitation Education an Research Hospital, PMR Clinic

DSI Lojmanları 1.Kısım B I Mustafa kemal Mahallesi

Çankaya Ankara, Turkey o6520 E-mail:

g_nakipoglu@yahoo.com

Disclaimer: There was no external funding in the preparation of this manuscript. Conflict of interest: None.

Manuscript received: o8-17-2012 Revised manuscript received: o9-19-2012 and 12-25-2012 Accepted for publication: 01-02-2013

Free full manuscript: www.painphysicianjournal.com
Background: Several studies have described pain prevalence, risk factors, pain and medical variables in spinal cord injury $(\mathrm{SCl})$ populations. In this study on traumatic $\mathrm{SCl}$ in Turkey, we surveyed the neuropathic pain experiences during in-patient rehabilitation and defined the relationships between neuropathic pain and demographic and $\mathrm{SCl}$ characteristics of patients.

Objectives: To survey the neuropathic pain experiences during in-patient rehabilitation in traumatic $\mathrm{SCl}$ and to define the relationships between neuropathic pain and demographic and SCl-related characteristics of patients.

Study Design: Descriptive study.

Setting: Physicial Medicine and Rehabilitation inpatient clinic, Ankara, TUrkey

Methods: Sixty-nine SCI patients as inpatients were included in this descriptive study. All patients demographic and $\mathrm{SCl}$-related characteristics were enrolled. The diagnosis of neuropathic pain was made with the Leeds Assessment of Neuropathic Symptoms and Signs (LANSS) Pain Scale. Location of pain and pain description, relation to time and severity according to McGill Pain Questionnaire (MPQ) were enrolled.

Results: The neuropathic pain localization was below the lesion level in 67 (97.1\%) and at the lesion level in $2(2.9 \%)$ patients. The pain was at the hip and leg regions in $36(52.2 \%)$ patients The neuropathic pain was defined as burning in 27 (39.1\%), aching in 26 (37.7\%), sharp in 4 (5.8\%), stinging in $3(4.3 \%)$, and cramping in $3(4.3 \%)$. We did not find a significant difference between demographic and $\mathrm{SCl}$-related characteristics and the localization of neuropathic pain for the patients $(P>0.05)$. There was no significant difference according to pain description by MPQ and pain localization $(P>0.05)$. We found a significant relationship between the patient's lesion level and the region of pain $(P<0.05)$.

Conclusion: We found the neuropathic pain due to $\mathrm{SCl}$ to be mostly below the lesion level with a burning or aching character and we did not find a significant relationship between the demographic and SCl-related characteristics of the patient and the pain characteristics.

Key words: Spinal cord injury, pain, neuropathic pain

Pain Physician 2013; 16:259-264 pinal cord injury $(\mathrm{SCl})$ is a complex disability, often requiring specialized knowledge and expertise to manage multisystem impairments. Pain is described by $\mathrm{SCl}$ patients as the worst problem, far more disabling than the loss of motor and sensory function. Reports of the pain prevalence differ between
18 and 96 percent (1), but is most often described as present in around $60-69 \%$ of the $\mathrm{SCl}$ population (2). Several studies have described pain prevalence, risk factors, pain and medical variables in $\mathrm{SCl}$ populations (3-6). In this study on traumatic SCl in Turkey, we surveyed the neuropathic pain experiences during 
in-patient rehabilitation and defined the relationship between neuropathic pain and demographic and $\mathrm{SCl}$ characteristics of patients.

\section{Methods}

\section{Participants}

We included a total of $69 \mathrm{SCl}$ patients chosen according to inclusion criteria from the 520 patients who took part in our rehabilitation program as in-patients at our hospital between June 2005 and June 2008. Study inclusion criteria were $\mathrm{SCl}$ for at least 6 months, age 18 years or older, presence of neuropathic pain, and consent to the study. A total of 451 patients were excluded from the study with 30 having non-traumatic $\mathrm{SCl}, 2$ with concurrent traumatic brain injury, 272 not having pain, 88 with an $\mathrm{SCl}$ of less than 6 months, and 59 suffering from SCl with non-neuropathic pain (Fig. 1).

The study was approved by the Institutional Review Board of our hospital.

\section{Demographic Characteristics}

The patients' age, gender, marital status, educational status, and occupational data were recorded.

\section{SCl Characteristics}

$\mathrm{SCl}$ etiology was classified as traffic accident, fire- arm injury, buried in wreckage, or other causes. The $\mathrm{SCl}$ level was categorized as C1-4, C5-8, T1-5, T6-12, and L1-4. The grading of $\mathrm{SCl}$ as complete or incomplete was based on the American Spinal Injury Association's (ASIA) impairment scale (7). The length of time betwween surgery and the event was recorded. Spasticity of the lower extremity was estimated by the Ashworth scale (8). The patients' motor activity was also evaluated. The motor activity under the lesion level was assessed. The superficial pain sensation level, and vibration, position, and pressure sensation were recorded as normal or disturbed. The presence of involuntary movement, hyperalgesia, and allodynia was also evaluated.

\section{Diagnosis of Neuropathic Pain}

The diagnosis of neuropathic pain was made with the Leeds Assessment of Neuropathic Symptoms and Signs (LANSS) Pain Scale (9). This scale, as first used by Bennett, is a very useful tool that provides immediate information in the clinical setting and helps distinguish nociceptive pain from neuropathic pain. The validity and reliability study for the Turkish population has been performed by Yucel et al (10).

\section{Location of Pain}

Pain location was assessed by a pain location checklist that asked respondents to rate the presence of pain

Total number of SCI patients that could have been admitted to inpatient department of the hospital $(n=520)$

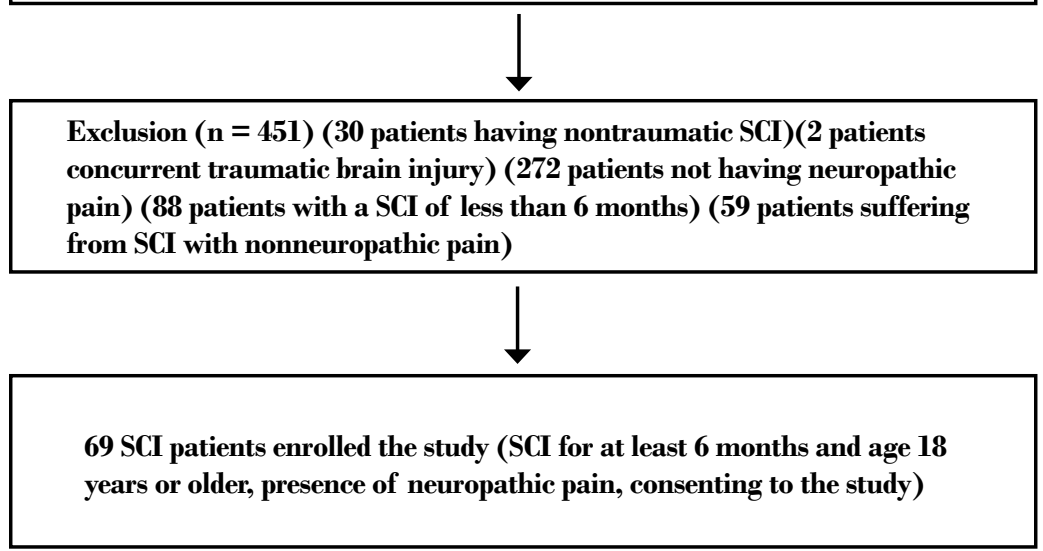

Fig. 1. Flow chart of Spinal Cord Injury (SCI) patients enrolled the of study. 
in 11 different locations including the neck, shoulder, arm-hand, upper back-lower back, hip-thigh, abdomen, and leg-foot. The localization of pain was also classified according to International Association for the Study of Pain criteria as neuropathic pain at the lesion level or below the lesion level (11).

\section{Pain Description, Relation to Time and Severity}

The McGill Pain Questionnaire (MPQ) was used to evaluate the sensory and perceptive description of pain, its relation with time, and its severity (12). The Turkish reliability and validity study of the MPQ has been performed by Kuguoglu and Aslan in 2003 (13).

\section{Pain Occurance}

Patients were asked if pain occurred during sleep, work, or daily activities.

\section{General Condition}

Patients were asked if they were sad, tired, or anxious due to the pain.

\section{Functional Status}

The patient's functional status on admission to and discharge from rehabilitation was assessed using the Functional Independence Measurement (FIM). The Turkish reliability and validity study has been performed by Kucukdeveci et al in 2001 (14).

\section{Treatment}

The treatments administered to the patients for neuropathic pain were also recorded.

\section{Complications}

$\mathrm{SCl}$-related complications such as neurogenic bladder, neurogenic bowel, spasticity, decubitus ulcer, deep vein thrombosis, pulmonary embolism, and sexual problems were recorded.

\section{Statistical Analyses}

Statistical analyses were performed using the Statistical Package for Social Sciences (SPSS) 11.0 software. The $\mathrm{x} 2$ was used to analyze the association between categorical variables. For continuous variables with normal distribution and non-normal distribution, the test and Mann-Whitney test were used, respectively. The level of statistical significance was set as $P<0.05$ for all tests.

\section{Results}

\section{Demographic Characteristics}

The mean age of the $\mathrm{SCl}$ patients included in the study was $38.09+11.12(18-78)$ with $15(21.7 \%)$ women and $54(78.3 \%)$ men. Fifty-two $(75.4 \%)$ were married and $16(23.2 \%)$ single. The educational status was primary school in 52 (75.4\%), high school in $8(11.6 \%)$, and secondary school in $6(8.7 \%)$. Forty-eight patients were employed $(69.6 \%), 11$ were housewives $(15.9 \%)$, 3 were students $(4.3 \%)$, and 2 were retired $(2.9 \%)$.

\section{SCl Characteristics}

The $\mathrm{SCl}$ etiology and level are given in Table 1 and Table 2, respectively. The lesion was complete in $25(36.2 \%)$ and incomplete in $44(63.8 \%)$, according to the ASIA scale. The number of patients that had undergone surgery the same month was 40 (58\%). The tonus was Ashworth 2 in $11(15.9 \%)$, normal in $14(20.3 \%)$, Ashworth 3 in $8(11.6 \%)$, Ashworth 1 in 6 $(8.7 \%)$, Ashworth 4 in 1 (1.4\%), and flaccid in 29 (42\%). Active movement under the lesion level was absent in $26(37.7 \%)$ patients and present in $43(62.3 \%)$.

The superficial touch pain sensation was disturbed below T12 in $12(17.4 \%)$, below T10 in $8(11.6 \%)$, and below L1 in $6(8.7 \%)$ patients. Vibration and position sensation was disturbed in $48(69.6 \%)$ and normal in $21(30.4 \%)$ patients. Pressure sensation was disturbed in $47(68.1 \%)$ patients and normal in $22(31.9 \%)$. There was no involuntary movement in 68 (98.6\%) of our

Table 1. Etiologies of spinal cord injury in our patients.

\begin{tabular}{|l|c|c|}
\hline Etiology & N & \% \\
\hline Traffic Accident & 22 & 31.9 \\
\hline Firearm Injury & 12 & 17.4 \\
\hline Falls & 14 & 20.3 \\
\hline Buried in wreckage & 11 & 15.9 \\
\hline Other Causes & 10 & 14.5 \\
\hline
\end{tabular}

Table 2. The Spinal Cord Injury(SCI) Levels of Patients

\begin{tabular}{|l|c|c|}
\hline \hline SCI Level & N & \% \\
\hline C1-4 & 4 & 5.8 \\
\hline C5-8 & 10 & 14.5 \\
\hline T1-5 & 7 & 10.1 \\
\hline T6-12 & 35 & 50.7 \\
\hline L1-S4 & 13 & 18.8 \\
\hline
\end{tabular}


patients. None of our patients had hyperalgesia or allodynia.

\section{Diagnosis of Neuropathic Pain}

The mean LANSS score was $15.65 \pm 3.03(10-21)$. (min-max)

\section{Pain Location}

The neuropathic pain localization was below the lesion level in $67(97.1 \%)$ and at the lesion level in 2 $(2.9 \%)$ patients. The pain was at the hip and leg regions in $36(52.2 \%)$, the back in $6(8.7 \%)$, and the legs and feet in $6(8.7 \%)$.

\section{Pain Definition, Relation to Time and Severity}

The neuropathic pain definitions are given in Table 3. We found the neuropathic pain developing as a result of $\mathrm{SCl}$ to mostly have a burning and aching character. The relation to time was chronic in 34 (49.3\%), intermittent in $27(39.1 \%)$, and acute in 8 (11.6\%). The intensity was discomforting in $38(55.1 \%)$, distressing in $16(23.2 \%)$, horrible in $13(18.8 \%)$, mild in one $(1.4 \%)$, and excruciating in one (1.4\%).

\section{The Occurance of the Pain}

When the patients were asked about the time of occurance of the pain, $32(46.4 \%)$ had constant pain, $16(23.2 \%)$ had pain during exercise, $13(18.8 \%)$ had pain during exercise and sleep, and $8(11.6 \%)$ had pain during sleep.

\section{General Condition}

The patients' general state was sad in $25(36.2 \%)$, tired in $2(2.9 \%)$, and anxious in one (1.4\%).

\section{Functional Status}

Fifty $(72.5 \%)$ were ambulatory while 19 (27.5\%) were using a wheelchair. The mean entry FIM was 79.6 +11.58 and the mean exit FIM $88.31+12.68$.

Table 3. Pain description according to McGill Pain Questionnaire in our patients.

\begin{tabular}{|l|c|c|}
\hline Pain description & N & \% \\
\hline Burning & 27 & 39.1 \\
\hline Aching & 26 & 37.7 \\
\hline Sharp & 4 & 5.8 \\
\hline Stinging & 3 & 4.3 \\
\hline Cramping & 3 & 4.3 \\
\hline Other & 6 & 8.4 \\
\hline
\end{tabular}

\section{Treatment}

The medication used was amitriptyline and nonsteroidal anti-inflammatory drugs (NSAIDs) in 13 (18.8\%), NSAID in 10 (14.5\%), amitriptyline in 9 (13\%), NSAID and gabapentin in $7(10.1 \%)$, and amitriptyline, NSAID, and gabapentin in $6(8.7 \%)$.

\section{Complications}

The complications were neurogenic bladder and bowel in 16 (23.2\%), neurogenic bladder and bowel and decubitus ulcer in $12(17.4 \%)$, neurogenic bowel and bladder and spasticity in $10(14.5 \%)$, and neurogenic bladder and bowel and deep vein thrombosis in $8(11.6 \%)$.

We did not find a significant difference between demographic characteristics and the localization of neuropathic pain for the patients included in the study $(P>0.05)$.

We did not find a significant difference between the patient groups younger and older than 38 and the neuropathic pain localization $(P>0.05)$.

There was also no statistically significant difference between the cause of the $\mathrm{SCl}$, whether it was complete or incomplete according to the ASIA disability scale, the injury level, and the neuropathic pain localization $(P>$ 0.05).

There was no statistically significant difference according to pain localization by MPQ and pain localization $(P>0.05)$.

There was no statistically significant difference between the paraplegic and tetraplegic patients for pain definition according to the MPQ, its relation with time, and its severity $(P>0.05)$.

We found a statistically significant relationship between the patient's lesion level and the region of pain $(P<0.05)$. Hip-thigh and leg-feet pain was present in 32 paraplegic and 4 tetraplegic patients.

\section{Discussion}

Norrbrink Budh et al (5) have found aching pain to be the most commonly used descriptor in their study aiming to define pain and determine the related values in $\mathrm{SCl}$ patients. Widerström-Noga et al (15) have reported that $55.4 \%$ of patients with $\mathrm{SCl}$-related neuropathic pain are tetraplegic, with the pain felt in multiple regions, but most commonly in the back region. The pain was most commonly described as burning or aching pain. Burning pain was found to be related to the frontal section of the torso and genitals together with the buttocks and lower extremities while aching pain was 
associated with the neck, shoulders, and upper back. Rintala et al (16) have evaluated the characteristics of individuals with chronic pain in the $\mathrm{SCl}$ population and its prevalence. They found the most common pain descriptors to be aching, sharp, hot-burning, and tiringexhausting. The distribution of our neuropathic pain patients was $21(30.4 \%)$ tetraplegics and 48 (69.6\%) paraplegics. In accordance with literature we found the neuropathic pain developing as a result of $\mathrm{SCl}$ to mostly have a burning and aching character. Unlike the literature, pain was reported in the hip and leg regions by $36(52.2 \%)$, the back by $6(8.7 \%)$, and the leg-feet by $6(8.7 \%)$ of our patients. We found no statistically significant difference for pain definition or the pain regions according to the MPQ.

Siddall et al (17) did not find a relationship between the presence of pain and the lesion level or completeness of injury or the type of injury, but neuropathic pain below the lesion level was more common in tetraplegic patients. Ulrich et al (3) found no relationship between the demographic and $\mathrm{SCl}$ features and the pain score, localization, or severity. Werhagen et al (18) found a lower incidence of neuropathic pain in patients below 20 years of age. They found neuropathic pain below the lesion level to be more frequent until the age of 39 , and neuropathic pain at the lesion level more frequent at the 40 and over group. They found no correlation between gender, injury level, and injury completeness. They only found a relationship between neuropathic pain below the lesion level and complete injury. Contrary to this literature, we did not find a significant difference between the patient groups younger and older than 38 years of age for neuropathic pain localization. Yap et al (19) did not find any relationship between injury completeness and the type of pain. Werhagen et al (20) have reported neuropathic pain below the lesion level to be more common in women.

Norrbrink Budh et al (2) did not find an effect on the number of painful body regions, pain severity, localization, occurance, and distribution. Yap et al (19) did not find a relationship between injury completeness, spinal surgery, and the type of pain in traumatic $\mathrm{SCl}$. Norrbrink Budh et al (5) have found a correlation between pain and mean injury age and gender in $\mathrm{SCl}$ patients and have reported neuropathic pain to be more common in patients with incomplete lesions. In line with most of literature, we did not find a statistically significant difference between demographic features and the localization of neuropathic pain in the patients included in our study. We found no statistically significant difference between the $\mathrm{SCl}$ cause, whether the injury was complete or incomplete according to the ASIA disability scale, the injury level, and the neuropathic pain localization.

Yap et al (19) have reported an increased incidence of musculoskeletal and neuropathic pain in paraplegic patients. Ulrich et al (3) have found upper extremity pain to be more common in patients with high-level injury compared to paraplegic patients. Pain was most commonly seen in the shoulders, lower back, neck, and arm in high cervical injuries and in the lower back, leg, and shoulders in paraplegics. They found neck pain to be more common in lower cervical injuries than in higher cervical injuries or paraplegics. Our patients with neuropathic pain were distributed as 48 (69.6\%) paraplegic and $21(30.4 \%)$ tetraplegics. There was no statistically significant difference between our paraplegic and tetraplegic patients regarding the MPQ results. We found a statistically significant difference between the patient's lesion level and the pain region. Hip-thigh and leg-feet pain was present in 32 paraplegics and 4 tetraplegics.

Finnerup et al (21) have reported the use of medication in neuropathic pain patients as $43 \%$ analgesic and $7 \%$ antidepressant or anticonvulsant. Our patients were using the following medical treatment: amitriptyline and NSAIDs in $13(18.8 \%)$, NSAIDs in 10 (14.5\%), amitriptyline in 9 (13\%), NSAIDs and gabapentin in 7 $(10.1 \%)$, and amitriptyline, NSAIDs, and gabapentin in $6(8.7 \%)$.

Werhagen et al (18) have reported pain at the lesion level in $15 \%$ and below the lesion level in $23 \%$ of neuropathic pain patients and that daily life was affected in $67 \%$ of those with pain. Norrbrink Budh et al (5) have found the neuropathic pain to be below the lesion level in $70.4 \%$ of the patients. The quality of life had been affected by the pain in 94 (32.3\%) of the 276 patients. Similar to the literature, neuropathic pain was below the lesion level in $67(97.1 \%)$ and at the lesion level in $2(2.9 \%)$ of the patients included in our study. When the patients were asked about the time of occurance of the pain, $32(46.4 \%)$ had constant pain, 16 $(23.2 \%)$ had pain during exercise, $13(18.8 \%)$ had pain during exercise and sleep, and $8(11.6 \%)$ had pain during sleep. The general state was sad in 25 (36.2\%), tired in $2(2.9 \%)$, and anxious in one $(1.4 \%)$.

\section{Conclusion}

We found neuropathic pain due to $\mathrm{SCl}$ to be mostly below the lesion level with a burning or aching char- 
acter and we did not find a significant relationship between the demographic and SCl-related features of the patient and the pain characteristics in accordance the literature. More research is needed to identify better ways to prevent, assess, and treat chronic pain in the $\mathrm{SCl}$ population.

\section{References}

1. Putzke JD, Richards JS, Hicken BL, Ness TJ, Kezar L, DeVivo M. Pain classification following spinal cord injury: The utility of verbal descriptors. Spinal Cord 2002 ; 40:118-127.

2. Norrbrink Budh C, Lund I, Hultling C, Levi R, Werhagen L, Ertzgaard P, Lunderberg T. Gender related differences in pain in spinal cord injured individuals. Spinal Cord 2003; 41:122-128.

3. Ullrich PM, Jensen MP, Loeser JD, Cardenas DD. Pain intensity, pain interference and characteristics of spinal cord injury. Spinal Cord 2008; 46:451-455.

4. Hanley MA, Masedo A, Jensen MP, Cardenas D, Turner JA. Pain interference in persons with spinal cord injury: Classification of mild, moderate, and severe pain. The Journal of Pain 2006; 7:129-133. 5. Norrbrink Budh C, Lund I, Ertzgaard P, Holtz A, Hultling C, Levi R, Werhagen $L$, Lundeberg T. Pain in a Swedish spinal cord injury population. Clinical Rehabilitation 2003; 17:685-690.

6. Jensen MP, Hoffman AJ and Cardenas DD. Chronic pain in individuals with spinal cord injury: A survey and longitudinal study. Spinal Cord 2005; 43:704-712.

7. Maynard FM Jr, Bracken MB, Creasey G, Ditunno JF Jr, Donovan WH, Ducker TB, Garber SL, Marino RJ, Stover SL, Tator $\mathrm{CH}$, Waters RL, Wilberger JE, Young W. International standards for neurologi- cal and functional classification of spinal cord injury. American Spinal Injury Association. Spinal Cord 1997; 35:266-274.

8. Bohannon RW, Smith MB. Interrater reliability of a modified Ashworth scale of muscle spasticity. Phy Ther 1987; 67:206-207.

9. Bennett M. The LANSS Pain Scale: The Leeds assessment of neuropathic symptoms and signs. Pain 2001; 92:147-157.

10. Yücel Y, Senocak M, Kocasoy-Orhan E, Çimen A, Ertas M. Results of Leeds assessment of neuropathic symptoms and signs pain scale in Turkey: A validation study. The Journal of Pain 2004; 5:427-432.

11. Siddall PJ, Taylor DA, Cousins MJ. Classification of pain following spinal cord injury. Spinal Cord 1997; 35:69-75.

12. Melzack R. The McGill Pain Questionnaire: Major properties and scoring methods. Pain 1975; 1:277-299.

13. Kuðuluoðlu S, Aslan FE. Adaptation of the McGill Pain Questionnaire for use in Turkey. Aðrý 2003; 15:47-51.

14. Küçükdeveci $A A$, Yavuzer $G$, Elhan $A H$, Sonel B. Adaptation of the functional independence measure for use in Turkey. Clinical Rehabilitation 2001; 15:311-318.

15. Widerström-Noga EG, Felipe-Cuervo $E$, Yezierski RP. Relationships among clinical characteristics of chronic pain after spinal cord injury. Arch Phys Med Rehabil
2001; 82:1191-1197.

16. Rintala $\mathrm{DH}$, Holmes $\mathrm{SA}$, Fiess $\mathrm{RN}$, Courtade D, Loubser, PG. Prevalence and characteristics of chronic pain in veterans with spinal cord injury. Journal of Rehabilitation Research \& Development 2005; 42:573-584.

17. Siddall PJ, McClelland JM, Rutkowski SB, Cousins MJ. A longitudinal study of the prevalence and characteristics of pain in the first 5 years following spinal cord injury. Pain 2003; 103:249-257.

18. Werhagen L, Budh CN, Hultling C, Molander C. Neuropathic pain after traumatic spinal cord injury - relations to gender, spinal level, completeness, and age at the time of injury. Spinal Cord 2004; 42:665-673.

19. Yap EC, Tow A, Menon EB, Chan KF, Kong $\mathrm{KH}$. Pain during in-patient rehabilitation after traumatic spinal cord injury. International journal of Rehabilitation Research 2003; 26:137-140.

20. Werhagen L, Hultling C, Molander C. The prevalence of neuropathic pain after non-traumatic spinal cord lesion. Spinal Cord 2007; 45:609-615

21. Finnerup NB, Johannesen IL, Sindrup $\mathrm{SH}$, Bach FW, Jensen TS. Pain and dysesthesia in patients with spinal cord injury: A postal survey. Spinal Cord 2001; 39:256-262. 